\title{
Tarefas exploratório-investigativas de ensino-aprendizagem- avaliação para o desenvolvimento do pensamento algébrico
}

Resumo: Este artigo apresenta os resultados de uma pesquisa sobre as manifestações de alunos dos Anos Iniciais em relação à potencialidade das tarefas exploratório-investigativas de ensino-aprendizagemavaliação para o desenvolvimento do pensamento algébrico. $\mathrm{O}$ aporte teórico baseou-se nos debates a respeito da avaliação para a aprendizagem e das tarefas exploratório-investigativas, no campo do pensamento algébrico. As atividades investigativas foram desenvolvidas em uma escola pública de ensino regular, localizada em um bairro periférico da cidade de Belém-PA, em uma turma do $4^{\circ}$ ano, composta por 24 estudantes. O percurso investigativo foi de natureza qualitativa, por meio da análise do desenvolvimento de tarefas de ensino-aprendizagem-avaliação, realizadas em sala de aula, por grupos de estudantes. As tarefas mostraram-se propícias para serem trabalhadas nos Anos Iniciais e pertinentes para articular ensinoaprendizagem-avaliação, por meio de feedback direcionado para o desenvolvimento do pensamento algébrico.

Palavras-chave: Pensamento Algébrico. Tarefas Exploratório-Investigativas. Avaliação Formativa. Anos Iniciais.

\section{Exploratory-investigative tasks of teaching-learning-evaluation in view of the algebraic thought development}

Juliana Batista Mescouto

Mestre em Docência em Educação em Ciências e Matemáticas.

Professora do Centro de Formação

Saberes Ka'apor. Pará, Brasil.

(iD) orcid.org/0000-0002-1244-4931

$\bowtie$ jhu.bsousa@gmail.com

Isabel Cristina Rodrigues de Lucena

Doutora em Educação. Professora do Programa de Pós-Graduação em

Educação em Ciências e Matemáticas e em Docência em Educação em

Ciências e Matemáticas, ambos da Universidade Federal do Pará (UFPA). Pará, Brasil.

(iD) orcid.org/0000-0001-9515-101X

$\square$ ilucena@ufpa.br

Elsa Barbosa

Doutora em Ciências da Educação. Professora do Centro de Investigação em Educação e Psicologia da Universidade de Évora. Évora, Portugal.

(iD) orcid.org/0000-0003-0034-5917

$\bowtie$ barbosa.elsa@gmail.com

Recebido em 03/03/2021 Aceito em 17/08/2021 Publicado em 31/08/2021

Abstract: This paper presents the results of a research on the student's manifestations at the Initial Years in relation to the potentiality of the exploratory-investigative tasks of teaching-learning-evaluation in view of the algebraic thought development. The theoretical contribution was based on the debates regarding the assessment for learning and the exploratory-investigative tasks, in the algebraic thinking field. The investigative activities were developed in a regular education public school, located in a peripheral neighborhood of Belém-PA, in a 4th grade class, composed by 24 students. The investigation was qualitative, through the analysis of the teachinglearning-evaluation tasks accomplished in the classroom, by groups of students. The tasks were considered favorable to be worked in the Initial Years and pertinent to combine teaching-learning-evaluation, by means of feedback directed for development of the algebraic thought.

Keywords: Algebraic Thinking. Exploratory-Investigative Tasks. Formative Assessment. Initial Years. 


\section{Tareas de enseñanza-aprendizaje-evaluación exploratoria- investigativa para el desarrollo del pensamiento algebraico}

Resumen: Este artículo presenta los resultados de una investigación sobre las manifestaciones de los estudiantes en los Primeros Años en relación con la potencialidad de las tareas exploratorias-investigativas de enseñanza-aprendizaje-evaluación para el desarrollo del pensamiento algebraico. El aporte teórico se basó en debates sobre la evaluación para el aprendizaje y las tareas exploratorias-investigativas en el campo del pensamiento algebraico. Las actividades de investigación se desarrollaron en una escuela pública de educación regular, ubicada en un barrio periférico de la ciudad de Belém-PA, en una clase de 4to grado, compuesta por 24 estudiantes. El camino investigativo fue de carácter cualitativo, a través del análisis del desarrollo de las tareas de enseñanzaaprendizaje-evaluación, realizadas en el aula, por grupos de estudiantes. Las tareas fueron favorables para ser trabajadas en los Primeros Años y relevantes para articular enseñanzaaprendizaje-evaluación, a través de la retroalimentación dirigida al desarrollo del pensamiento algebraico.

Palabra clave: Pensamiento Algebraico. Tareas Exploratorias-Investigativas. Evaluación Formativa. Primeros Años.

\section{Introdução}

A orientação curricular brasileira para a Educação Básica tem como referência a Base Nacional Curricular Comum (BNCC), promulgada em 2017. Este documento indica que é "imprescindível que algumas dimensões do trabalho com álgebra estejam presentes nos processos de ensino e aprendizagem desde o Ensino Fundamental — Anos Iniciais" (BRASIL, 2017, p. 268), pois elas podem potencializar competências e habilidades cognitivas que estão além dos números e operações e assim contribuir para a análise de relações e situações matemáticas necessárias para o entendimento da Álgebra nos anos posteriores. Desde os Anos Iniciais do Ensino Fundamental há menção da unidade temática Álgebra, com o objetivo de desenvolver o pensamento algébrico a fim de subsidiar a compreensão de modelos matemáticos que exigem representações e análises de relações quantitativas de grandezas, situações e estruturas matemáticas. Destaca ainda que, nessa fase da escolarização, não se deve propor o uso de letras para expressar regularidades.

A BNCC (BRASIL, 2017, p. 270) expressa que a unidade temática Álgebra "tem como finalidade o desenvolvimento de um tipo especial de pensamento - pensamento algébrico - que é essencial para utilizar modelos matemáticos na compreensão, representação e análise de relações quantitativas de grandezas e, também, de situações e 
estruturas matemáticas, fazendo uso de letras e outros símbolos". Com intuito de pesquisa sobre o pensamento algébrico em práticas letivas e como discente do curso de mestrado profissional, a primeira autora deste artigo propôs-se a investigar manifestações de estudantes dos Anos Iniciais frente ao desenvolvimento do pensamento algébrico por meio de tarefas exploratório-investigativas considerando a integração ensinoaprendizagem-avaliação.

Este artigo apresenta alguns resultados da dissertação de mestrado profissional (MESCOUTO, 2019), desenvolvida no âmbito do projeto de pesquisa interinstitucional intitulado Ensino-aprendizagem-avaliação em Matemática nos Anos Iniciais do Ensino Fundamental: atividades exploratório-investigativas e formação docente, desenvolvido entre a Universidade Federal do Pará e o Centro Universitário Univates, do Rio Grande do Sul (CNPq - Edital Universal n. 01/2016), com vigência até março de 2020.

Para o estudo, desenvolveu-se as atividades investigativas em uma escola pública de Ensino Fundamental, nos Anos Iniciais, localizada na cidade de Belém, no estado do Pará, e partiu da seguinte questão de pesquisa: de que modo as tarefas exploratórioinvestigativas de ensino-aprendizagem-avaliação potencializam o desenvolvimento do pensamento algébrico de crianças nos Anos Iniciais? Desta forma, teve-se como objetivo geral investigar as manifestações de estudantes dos Anos Iniciais de uma escola pública de Belém-PA em relação às potencialidades das tarefas exploratório-investigativas de ensino-aprendizagem-avaliação para o desenvolvimento do pensamento algébrico. Devendo-se, para tal: (i) construir um conjunto de tarefas exploratório-investigativas voltadas para o ensino-aprendizagem-avaliação; (ii) possibilitar aos estudantes momentos de exploração, investigação e justificação oral e escrita de suas descobertas matemáticas; e (iii) identificar o pensamento algébrico e classificar os níveis de generalizações apresentadas nas estratégias de resolução dos estudantes do $4^{\circ}$ ano dos Anos Iniciais do Ensino Fundamental.

O aporte teórico que orientou a pesquisa encontra-se entre os debates a respeito da avaliação para a aprendizagem e das tarefas exploratório-investigativas, no campo do pensamento algébrico. Este inclui desde a avaliação, na perspectiva formativa (BLACK e WILLIAM, 1998, 2009; FERNANDES, 2004, 2011a; VILLAS-BOAS, 2008), e o paradigma da interação social (FERNANDES, 2011b), bem como Borralho, Lucena e Brito (2015) e Perrenoud (1999). Acrescentou-se ainda à discussão Canavarro, Oliveira 
e Menezes (2012), Ponte (2010) e Ponte, Nunes e Quaresma (2012), discorrendo sobre as tarefas exploratório-investigativas. Por fim, foi preciso, ao longo do desenvolvimento da pesquisa, ampliar as discussões a respeito da participação dos estudantes e do pensamento algébrico, com autores como Blanton e Kaput (2005), Canavarro (2007), Kieran (2011), Barbosa (2019), que auxiliaram na construção dos materiais didáticos utilizados na pesquisa aqui apresentada junto com a teoria do pensamento funcional e relacional ou aritmética generalizada (CARRAHER e SCHLIEMANN, 2007; BLANTON, 2008; BARBOSA, 2019).

\section{O pensamento algébrico}

Nos últimos anos, foram levantadas discussões a respeito do pensamento algébrico em um esforço para melhor compreender o tema, pois conforme Lins e Gimenez (1997, p. 89), ainda "não há consenso a respeito do que seja pensar algebricamente". No entanto, neste artigo, iremos apresentar algumas proposições encontradas na literatura em relação a esses questionamentos, que fizeram parte dos suportes teóricos usados na pesquisa.

Pesquisadores como Maria Blanton e James Kaput dedicam-se a pesquisas que buscam ampliar as discussões a respeito do pensamento algébrico. Esses dois investigadores conduziram, no National Center for Improving Students Learning and Achievement in Mathematics and Science (NCISLA), pesquisas pioneiras sobre esse tipo de pensamento nos primeiros anos de escolaridade em Massachusetts, Estados Unidos da América (EUA), e, para eles, o pensamento algébrico é entendido como o "processo pelo qual os alunos generalizam ideias matemáticas a partir de um conjunto de casos particulares, estabelecem essas generalizações através de discurso argumentativo, e expressam-nas de formas progressivamente mais formais e adequadas à sua idade" (BLANTON e KAPUT, 2005, p. 413). Essa concepção aproxima-se das ideias de Verschaffel, Greer e De Corte (2007), ao considerar que o pensamento algébrico está relacionado com o reconhecimento do que é geral em uma dada situação matemática e sua representação por meio de generalização.

Fiorentini, Miorim e Miguel (1993, p. 87) discutem que a existência do pensamento algébrico pode ser caracterizada nas situações em que esteja presente a 
"percepção de regularidades, percepção de aspectos invariantes em contraste com outros que variam, tentativas de expressar ou explicitar a estrutura de uma situação-problema e a presença do processo de generalização". Nesse sentido, quando os estudantes são levados a "descobrir e comprovar propriedades que se verificam em toda uma classe de objetos", segundo Ponte, Branco e Matos (2009, p. 10), estão a desenvolver o pensamento algébrico. Além disso, os autores também consideram essencial o trabalho com regularidades, pois representa "uma das vias privilegiadas para promover este raciocínio" (PONTE, BRANCO e MATOS, 2009, p. 10). Estudos realizados por Blanton e Kaput (2005) indicam que há duas portas de entrada para a promoção do pensamento algébrico: o pensamento funcional e o pensamento relacional.

O pensamento funcional está relacionado com a ideia de variação de quantidades, que é a mesma ideia do conceito de função em Matemática. Apesar desse conceito ser tratado com mais ênfase nos Anos Finais do Ensino Fundamental e no Ensino Médio, Beck e Silva (2015, p. 204) enfatizam que "existem situações-problema e tarefas que podem ser realizadas desde os anos iniciais do ensino fundamental com o objetivo de desenvolver o pensamento funcional nos estudantes".

O pensamento relacional ou Aritmética Generalizada ${ }^{1}$ consiste em olhar para os números sem focar exclusivamente nos procedimentos de cálculos; centrar-se na sua compreensão e no uso de um conjunto de relações existentes, bem como nas propriedades das operações e no sinal de igualdade.

De acordo com Carraher e Schliemann (2007), se o ensino estiver voltado somente para os aspectos centrais da Aritmética, os estudantes correrão o risco de conceber a Matemática de modo artificial e sem estímulo para a generalização. É essencial que eles desenvolvam desde cedo um pensamento matemático sólido que permita construir, a partir da Aritmética, elementos para o desenvolvimento do pensamento algébrico. Os autores ainda enfatizam que por mais que os números e operações sejam essenciais para os estudantes raciocinarem algebricamente isso não significa que eles estejam atentos a elementos centrais da Matemática, como a generalização, o que, segundo Mason² (1996)

\footnotetext{
${ }^{1}$ Optou-se por usar o termo pensamento relacional.

${ }^{2}$ MASON, John. Expressing generality and roots of algebra. In: BEDNARZ, Nadine; KIERAN, Carolyn; LEE, Lesley. (Ed.). Approaches of algebra: perspectives for research and teaching. Dordrecht: Kluwer Academic Publishers, 1996, p. 65-86.
} 
apud Mestre (2014, p. 20), é metaforicamente considerada como o "coração da Matemática”.

Assim, deve-se priorizar que os estudantes identifiquem regularidades e padrões de sequências numéricas ou não numéricas que sejam capazes de estabelecer leis matemáticas em diversos contextos, que mostrem relações de interdependência entre grandezas, além de manifestar habilidades de criação, interpretação e consigam transitar nas representações gráficas e simbólicas, bem como compreendam os procedimentos utilizados na resolução de problemas. Ribeiro e Cury (2015) consideram oportuno que sejam realizadas tarefas que busquem desenvolver o pensamento algébrico, desde os Anos Iniciais, o que poderá representar uma oportunidade para os estudantes realizarem abstrações e generalizações que estão na base dos processos de modelagem matemática da vida real e que fazem parte de um conjunto de experiências vindas de números, de padrões, de entes geométricos e de análise de dados.

Ponte (2010) enfatiza que atividades abertas de natureza exploratórioinvestigativa têm ganhado espaço nos currículos escolares, principalmente na disciplina de Matemática, uma vez que o desenvolvimento de tarefas com o propósito de envolver ativamente os estudantes é propício, visto que, em qualquer disciplina escolar, os estudantes aprendem quando mobilizam seus recursos cognitivos e afetivos com vista a alcançar um objetivo. No entanto, é necessário salientar a complexidade do papel do professor no ensino exploratório, uma vez que neste contexto terá de assumir desde a elaboração ou escolha da tarefa, perpassando o planejamento da aula, a apresentação das tarefas, o seu desenvolvimento, com o objetivo de nortear os conhecimentos matemáticos dos estudantes (OLIVEIRA e BASNIAK, 2021). A esse respeito, iremos tecer uma breve reflexão, a seguir.

\section{Tarefas exploratório-investigativas}

As palavras exploração e investigação podem assumir diferentes significados, dependendo do contexto em que estão inseridas. Neste artigo, essas palavras são usadas para designar uma modalidade de tarefa usada no ensino de conteúdos da disciplina Matemática. De acordo com Ponte (2010), as tarefas podem ser classificadas pelo grau de complexidade, estrutura, tempo e contextos diversos. Considerando aqui as duas 
primeiras dimensões, o grau de complexidade e a estrutura, as tarefas podem ter níveis de complexidade reduzidos ou elevados e ser classificadas como abertas ou fechadas. As tarefas abertas podem ser explorações (desafio menos elevado) ou investigações (desafio elevado) e ambas pretendem estimular o desenvolvimento de novos conceitos e o uso criativo de conceitos já existentes. As tarefas fechadas podem ser os exercícios (desafio reduzido) e os problemas (desafio elevado) e têm por objetivo a aplicação dos conhecimentos que os estudantes já possuem, em outras palavras, é aquela onde claramente se sabe o que é dado ou pedido.

Ponte (2010, p. 22) salienta que "muitas vezes não se distingue entre tarefas de investigação e de exploração, chamando-se investigações a todas elas". Segundo o autor, isso acontece porque fica difícil estabelecer o grau de dificuldade que uma tarefa pode representar a determinado grupo de estudantes. Por essa razão, neste artigo, optou-se por utilizar a expressão tarefas exploratório-investigativas.

As investigações e explorações pretendem trazer para a sala de aula o verdadeiro “espírito matemático", já que o estudante é chamado a agir como um matemático, não só na formulação de conjecturas e na realização de provas e refutações, mas também na exposição das suas descobertas para seus colegas e professor, pois o processo investigativo, no qual eles se envolvem durante o desenvolvimento das tarefas, potencializa "descobrir novas relações entre conceitos, a ter mais segurança nas suas ideias matemáticas e a desenvolver o raciocínio e a criatividade" (FONSECA, BRUNHEIRA e PONTE, 1999, p. 4).

As atividades de caráter exploratório, em que os estudantes se envolvem durante a resolução das tarefas tornam-se mais ricas. Inicialmente eles podem até chegar a resultados insatisfatórios, mas logo têm a oportunidade de perceber seus erros e reorganizar os dados em busca de novas soluções. Algumas vezes, o estudante também pode seguir por caminhos que o professor não tinha pensado e surgem resultados surpreendentes. Assim, o professor precisa estar atento a essas descobertas e disponível para apoiar as aprendizagens dos estudantes por meio de feedback continuado e de qualidade. Neste contexto, cabe ao professor ser criativo na gestão curricular e na preparação de aulas. As tarefas devem ser simultaneamente de ensino, aprendizagem e avaliação, devendo transmitir, ao estudante, informações claras e precisas sobre o seu conhecimento. O feedback fornecido deve apoiar os estudantes na sua aprendizagem 
(BARBOSA, 2019).

Em suma, o desenvolvimento do pensamento algébrico implica mudança das conceções dos professores sobre o significado de ensinar e aprender Matemática. Ou seja, é fundamental dar aos estudantes a oportunidade de explorar padrões e relações numéricas generalizando-as (BARBOSA, 2019). Neste contexto, de acordo com a autora, é possível afirmar que o desenvolvimento do pensamento algébrico se coaduna com uma organização de sala de aula em que os estudantes e os professores assumem um papel ativo, onde se trabalha tarefas exploratório-investigativas, por meio das quais se aprende, ensina e avalia.

\section{Metodologia}

Este estudo foi desenvolvido dando ênfase a procedimentos de caráter qualitativo e ocupou-se em estudar mais o contexto e os procedimentos de investigação do que simplesmente o resultado ou produto da pesquisa. Trata-se então de uma investigação qualitativa, descritiva e indutiva, alicerçada na concepção de tarefas de ensinoaprendizagem-avaliação para o desenvolvimento do pensamento algébrico.

O levantamento de informações foi realizado em uma escola pública que atende aos Anos Iniciais do Ensino Fundamental, localizada na periferia da cidade de BelémPA, em uma turma do $4^{\circ}$ ano do ensino regular, composta por 24 estudantes, sendo 13 meninos e 11 meninas, com idade entre 9 e 10 anos. A escolha da turma ocorreu porque os estudantes ainda não haviam vivenciado experiências que envolvessem atividades para o desenvolvimento do pensamento algébrico.

A pesquisadora não era a professora titular da turma e a aproximação com o lócus da pesquisa ocorreu durante encontros formativos, voltados à formação continuada de professores da referida escola, realizados periodicamente na escola por meio do projeto Ensino-aprendizagem-avaliação em Matemática nos Anos Iniciais do Ensino Fundamental: atividades exploratório-investigativas e formação docente.

Os estudantes foram organizados em grupos de até cinco componentes, de acordo com a afinidade entre eles. Quando necessário, houve alteração na composição das equipes. Apesar de ser uma tarefa exigente, a formação dos grupos de trabalho é fundamental para o sucesso deste tipo de ensino (BARBOSA, 2007). A escolha da 
formação dos grupos foi com a intenção de estimular as interações construtivas entre os estudantes para que, no confronto de ideias, surgissem novas aprendizagens.

Em cada encontro foi desenvolvida uma tarefa com a finalidade de investigar as manifestações dos estudantes em relação às potencialidades das tarefas exploratórioinvestigativas, de ensino-aprendizagem-avaliação, para o desenvolvimento do seu pensamento algébrico. Para tal, os grupos receberam uma cópia da tarefa impressa, em folha de papel A4, e, no final, as folhas respondidas eram recolhidas, para a verificação das justificativas e possíveis manifestações do pensamento algébrico. Durante o desenvolvimento das tarefas propostas, a atenção da pesquisadora era dispensada a todos os grupos, dando foco às resoluções das questões para gerar registros sobre como os grupos estavam discutindo e tentando resolver as questões, quais dúvidas e dificuldades e o que era possível fazer para ajudá-los a superá-las.

Para evitar a perda de informações importantes durante o desenvolvimento das tarefas, foram distribuídos, de modo estratégico, quatro gravadores de áudio entre os grupos para captar os diálogos e discussões. Salienta-se que, no início, os estudantes se sentiram incomodados com a presença dos gravadores de áudio, mas, aos poucos, eles se familiarizaram e compreenderam que as falas seriam utilizadas exclusivamente para interesse da pesquisa.

No que diz respeito à identificação dos estudantes, esta foi elaborada resguardando a identidade de cada um deles. Cada estudante recebeu um número, em um grupo formado com quatro componentes, e foi identificado pela letra A, da seguinte maneira: A1, A2, A3 e A4. Já os grupos foram identificados pela letra $\mathrm{G}$ e um número correspondente à quantidade de grupos formados no encontro. Por exemplo, no encontro em que foram formados quatro grupos, cada um foi identificado da seguinte maneira: G1, G2, G3 e G4.

Os procedimentos para a análise dos dados foram realizados, após cada encontro, por meio dos registros escritos e das transcrições dos áudios. De posse do material recolhido, passou-se a pensar no quadro de análise baseado, em primeiro lugar, no enquadramento teórico que sustenta essa pesquisa; em seguida, com as evidências dos dados recolhidos. Nesse sentido, foram analisadas individualmente as justificativas de todas as alternativas das tarefas, de acordo com o Domínio 1 - Pensamento funcional; e Domínio 2 - Pensamento relacional, ambos classificados em níveis. 
- Domínio 1 - Pensamento funcional

Quadro 1: Níveis de pensamento funcional

\begin{tabular}{|c|c|c|}
\hline \multicolumn{2}{|c|}{ Níveis de pensamento funcional } \\
\hline Nível 1 & Não Funcional & $\begin{array}{c}\text { Não há evidências do reconhecimento das } \\
\text { relações entre variáveis }\end{array}$ \\
\hline Nível 2 & Reconhece relações & Há o reconhecimento da relação entre variáveis \\
\hline Nível 3 & Pensamento funcional & $\begin{array}{c}\text { Há identificação explícita da relação entre a } \\
\text { variável independente e dependente }\end{array}$ \\
\hline
\end{tabular}

Fonte: Elaborado pelas Autoras

O nível 1 é considerado como não funcional, por não identificar qualquer aspecto do pensamento funcional; já, no nível 2, reconhece relações, existe a identificação da mudança em uma das variáveis, mas sem estabelecer uma ligação entre a variável dependente e a independente. No nível 3, pensamento funcional, há identificação explícita da relação entre a variável dependente e a variável independente.

\section{- Domínio 2 - Pensamento relacional}

Quadro 2: Níveis de pensamento relacional

\begin{tabular}{|c|c|c|}
\hline \multicolumn{2}{|c|}{ Níveis de pensamento relacional } \\
\hline Nível 1 & Não relacional & $\begin{array}{c}\text { Centra-se nos procedimentos de cálculos e não reconhece } \\
\text { relações numéricas e/ou propriedades das operações }\end{array}$ \\
\hline Nível 2 & $\begin{array}{c}\text { Uso de exemplos } \\
\text { particulares }\end{array}$ & $\begin{array}{r}\text { Reconhece relações numéricas e/ou propriedades das } \\
\text { operações em exemplos particulares }\end{array}$ \\
\hline Nível 3 & Relacional & $\begin{array}{c}\text { Reconhece e usa relações numéricas e/ou propriedades das } \\
\text { operações, para além dos casos particulares, evidenciando } \\
\text { sua generalização }\end{array}$ \\
\hline
\end{tabular}

Fonte: Elaborado pelas Autoras

No nível 1, não relacional, não há evidências de qualquer aspecto que envolva o pensamento relacional. No nível 2, uso de exemplos particulares, há o reconhecimento de relações numéricas, de propriedades das operações e do sinal de igualdade somente nos casos apresentados. No nível 3, o relacional, as ligações estão além dos casos particulares e revelam o reconhecimento de relações numéricas, propriedades das operações e o sinal de igualdade em casos gerais.

$\mathrm{Na}$ apresentação dos resultados, foram utilizados recortes dos diálogos estabelecidos durante o desenvolvimento das tarefas, incluindo as falas dos membros dos grupos e da pesquisadora. Assim, a identificação das manifestações do pensamento 
algébrico é destacada em itálico e enriquecida com imagens dos registros escritos dos estudantes. Neste item, são apresentadas e discutidas as experiências de ensino com as tarefas exploratório-investigativas para o ensino-aprendizagem-avaliação. Neste artigo, trazemos duas das quatro tarefas que foram trabalhadas durante a pesquisa. Primeiro, apresentamos a Tarefa 1 - Frutas Típicas e, depois, a Tarefa 2 -Azulejos Portugueses, ambas para o pensamento funcional e analisadas de acordo com o domínio 1.

\subsection{Tarefa 1 - Frutas Típicas}

A tarefa 1 era composta por um atributo (tipo de objeto) e com apenas dois objetos diferentes: cupuaçu e bacuri. Essa tarefa está na perspectiva do pensamento funcional como contexto para a promoção de generalização, que é considerada uma das vias privilegiadas para o pensamento algébrico.

Nessa perspectiva, o objetivo da tarefa foi a identificação da relação entre as variáveis dependentes e independentes da sequência, para a obtenção de regularidades que ocorriam em todos os termos da sequência, a fim de pensar em uma regra geral.

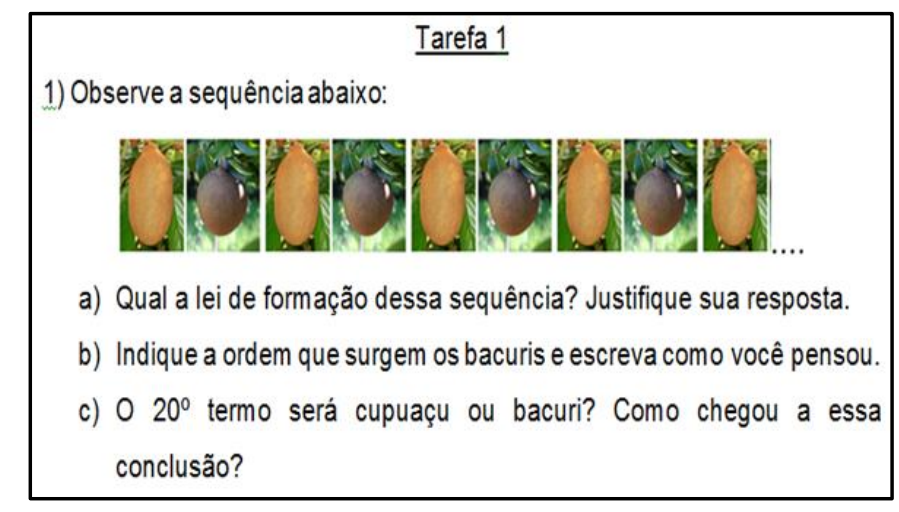

Figura 1: Tarefa 1 (Acervo da Pesquisa)

O desenvolvimento desta tarefa foi realizado logo no primeiro encontro com a turma, que ocorreu em uma sexta-feira, do mês de março, com a presença de 24 estudantes. Inicialmente, foram apresentados os objetivos da aula e da tarefa. Em seguida, os estudantes foram orientados para que a atividade fosse realizada em pequenos grupos, por isso, eles precisavam formar seis grupos com quatro componentes.

\subsection{Tarefa 2 - Azulejos Portugueses}

A tarefa 2 possuía um atributo (tipo de objeto) representado, nesse caso, por azulejos iguais. Essa tarefa encontrava-se dentro da perspectiva do pensamento funcional 
como caminho para a generalização, como via privilegiada para o desenvolvimento do pensamento algébrico. Nesse tocante, o objetivo foi desenvolver o pensamento algébrico por meio da observação dos aspectos comuns nos casos particulares da sequência, definindo uma regra geral e identificando as relações entre os termos da sequência e a ordem ocupada.

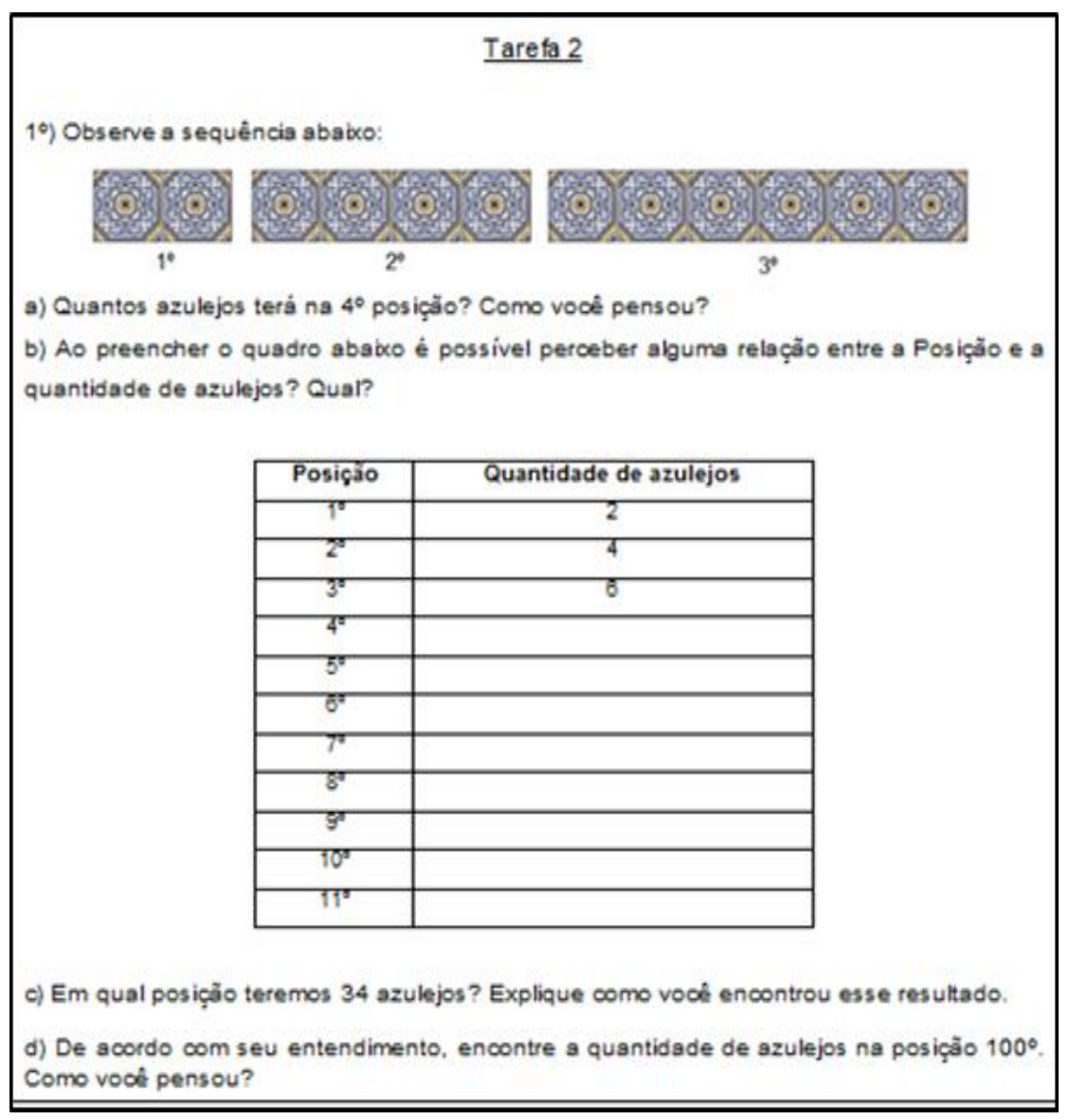

Figura 2: Tarefa 2 (Acervo da Pesquisa)

Esta tarefa foi realizada no segundo encontro com a turma. Ao chegar à sala de aula, os estudantes foram organizados em quatro grupos, com quatro componentes cada um. A sala de aula, nesse dia tinha 16 estudantes e, novamente, foi enfatizada a importância do trabalho em equipe, em que cada estudante deveria se envolver com a tarefa para que todos os membros pudessem encontrar regularidades, fazer generalizações, continuar a sequência, entendendo o sentido da repetição dos objetos, entre tantas outras orientações importantes para o bom desenvolvimento da tarefa. Após a apresentação inicial dos objetivos da aula, foram entregues as tarefas para os grupos, em seguida, foi feita a leitura coletiva, pontuando os principais objetivos da tarefa e foram 
esclarecidas as dúvidas existentes. Após esse momento, iniciou-se o trabalho autônomo dos grupos.

\subsection{Questões}

As questões formuladas para orientar as tarefas direcionavam os estudantes a repensar seu olhar sobre o conhecimento matemático. Nesse sentido, os comandos das questões obedeceram a diferentes formatos discursivos: a pergunta e o pedido de justificativa da resposta (Qual a lei de formação dessa sequência? Justifique sua resposta); uma afirmativa ou pergunta e o pedido de justificativa (Indique a ordem que surgem os bacuris e escreva como você pensou. O $20^{\circ}$ termo será cupuaçu ou bacuri? Como chegou a essa conclusão?).

Além desse tipo de questão, foram formuladas perguntas que orientavam os estudantes a refletir sobre o caminho que os levaram à resposta: quantos azulejos teremos na $4^{\mathrm{a}}$ posição? Como você pensou? De acordo com seu entendimento, encontre a quantidade de azulejos na posição 100a . Como você pensou? Em qual posição teremos 34 azulejos? Explique como você encontrou esse resultado. Ao preencher o quadro abaixo, é possível perceber alguma relação entre a posição e a quantidade de azulejos? Qual?

A seguir, nos resultados, serão apresentados alguns dos direcionamentos dessas perguntas.

\section{Resultados}

- Tarefa 1 - Frutas Típicas, Questão 1, Alternativa B, Grupo G3: Indique a ordem que surgem os bacuris e escreva como você pensou.

O grupo G3 indicou que os bacuris apareciam em posições pares e que variavam de dois em dois:

G3A1: O bacuri aparece sempre depois do cupuaçu.

Pesquisadora: Os bacuris aparecem em quais posições?

G3A2: Na $2^{a}, 4^{a}, 6^{a}, 8^{a}$ posição.

Pesquisadora: Para por aí?

G3A3: Vai continuar nas outras posições, de dois em dois.

G3A4: O dois é número par, os bacuris aparecem nas posições pares. 


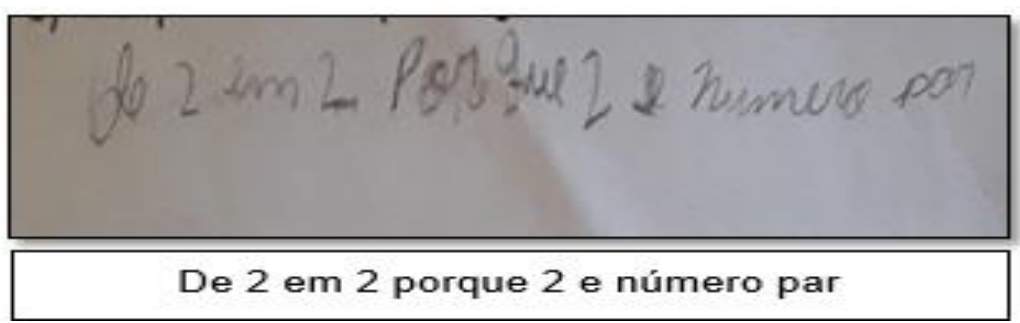

Figura 5: Justificativa do grupo G3 em relação à alternativa B da tarefa 1 (Acervo da Pesquisa)

A partir dos casos particulares, o grupo G3 reconheceu aspectos comuns em cada termo da sequência e estabeleceu uma regra geral que possibilitou encontrar todas as posições ocupadas pelos bacuris, por meio da identificação da relação entre as variáveis correspondentes a posição e a frutas: "O dois é número par, os bacuris aparecem nas posições pares" (G3A4). Sabendo que os bacuris ocupam posições pares, foi possível encontrar termos mais distantes na sequência.

- Tarefa 1 - Frutas típicas, Questão 1, Alternativa C, Grupo G4: O 20 termo será cupuaçu ou bacuri? Como chegou a essa conclusão?

O grupo G4 afirmou que o $20^{\circ}$ termo seria bacuri:

G4A1: Vai ser bacuri.

Pesquisadora: Como vocês pensaram?

G4A1: Simples, professora, a gente viu que os bacuris sempre aparecem nas ordens pares e como 20 é par, vai ser bacuri.

Pesquisadora: Muito bem!

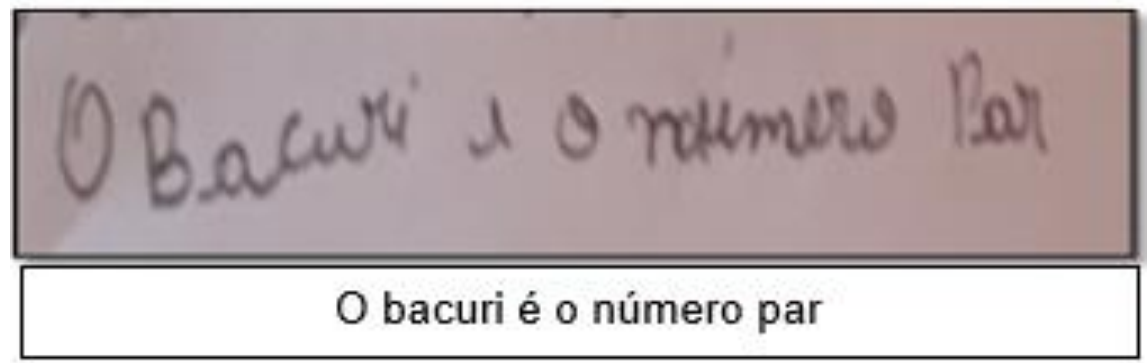

Figura 6: Justificativa do grupo G4 em relação à alternativa $\mathrm{C}$ da tarefa 1(Acervo da Pesquisa)

O grupo G4 identificou o padrão de crescimento da sequência por meio da generalização e estabeleceu uma regra geral, ao considerar que os bacuris sempre estavam em posições pares. A partir dos casos particulares, o grupo chegou à conclusão de que na $20^{\mathrm{a}}$ posição haveria um bacuri.

- Tarefa 2 - Azulejos Portugueses, Questão 1, Alternativa B, Grupo G2: Ao 
preencher o quadro abaixo, é possível perceber alguma relação entre a posição e a quantidade de azulejos? Qual?

O grupo G2 iniciou preenchendo o quadro de acordo com seu entendimento:

G2A1: Está aumentando de dois em dois.

G2A2: Está dobrando a quantidade de dois em dois.

Pesquisadora: Vocês percebem alguma relação entre a posição e a quantidade de azulejos?

G2A3: Está dobrando a posição e a gente descobre os azulejos.

Pesquisadora: Como é dobrar?

G2A1: É multiplicar por dois.

Pesquisadora: Muito bem!

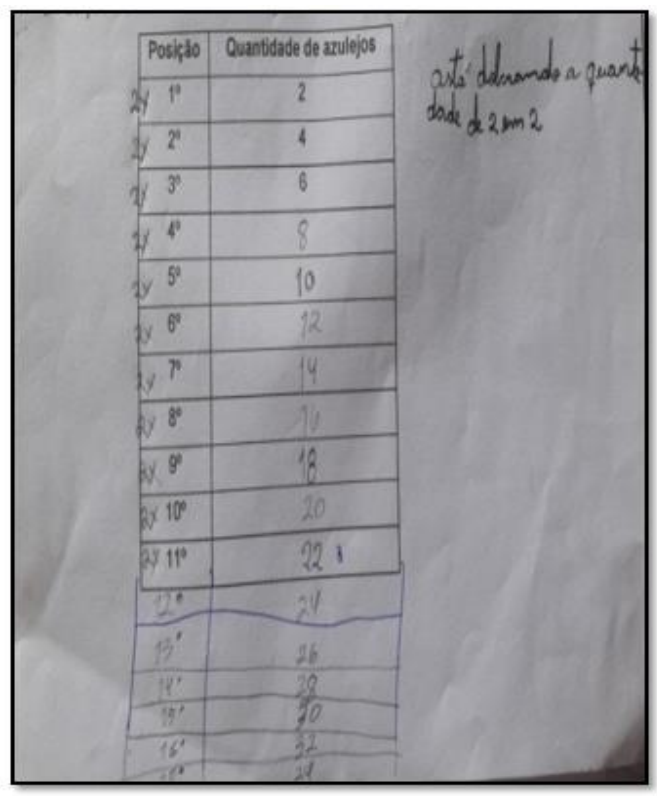

\begin{tabular}{||c|c|}
\hline Posição & $\begin{array}{c}\text { Quantidade de } \\
\text { azulejos }\end{array}$ \\
\hline $1^{\circ}$ & 2 \\
\hline $2^{\circ}$ & 4 \\
$\begin{array}{c}\text { Está } \\
\text { dobrando } \\
\text { a quantidade } \\
\text { de } 2 \text { em } 2\end{array}$ \\
\hline $3^{\circ}$ & 6 \\
\hline $4^{\circ}$ & 8 \\
\hline $5^{\circ}$ & 10 \\
\hline $6^{\circ}$ & 12 \\
\hline $7^{\circ}$ & 14 \\
\hline $8^{\circ}$ & 16 \\
\hline $9^{\circ}$ & 18 \\
\hline $10^{\circ}$ & 20 \\
\hline $11^{\circ}$ & 22 \\
\hline 12 & 24 \\
\hline 13 & 26 \\
\hline 14 & 28 \\
\hline 15 & 30 \\
\hline 16 & 32 \\
\hline 17 & 34 \\
\hline
\end{tabular}

Figura 7: Justificativa do grupo G2 em relação à alternativa B da tarefa 2 (Acervo da Pesquisa)

O grupo G2 evidenciou explicitamente que há uma relação entre a posição e a quantidade de azulejos: "Está dobrando a posição e a gente descobre os azulejos" (G2A3), ou seja, para encontrar a quantidade de azulejos, basta multiplicar o número correspondente às posições por dois: "É multiplicar por dois" (G2A1). Por meio da regra geral estabelecida, foi possível encontrar a quantidade de azulejos em posições distintas.

- Tarefa 2 - Azulejos Portugueses, Questão 1, Alternativa A, Grupo G4: Quantos azulejos teremos na $4^{a}$ posição? Como você pensou?

O grupo estabeleceu uma relação entre a posição e a quantidade de azulejos: 
G4A1: Está aumentando de dois em dois.

G4A2: Na quarta posição, vai ser oito azulejos.

Pesquisadora: Como vocês pensaram?

G4A2: Em cada posição, aumenta dois azulejos, na primeira é dois, depois aumenta mais dois e fica quatro, depois aumenta dois e fica seis e na quarta posição aumenta mais dois e fica oito.

G4A3: Professora, se somar duas vezes a posição quatro, vai dar a quantidade de azulejos.

Pesquisadora: Essa relação acontece somente neste caso?

G4A4: Não, professora, acontece em todas as posições. Olha aqui, na posição 1 é só somar 1+1 e vai ser dois azulejos; na posição 2, soma $2+2$, vai ser quatro azulejos; na posição 3 vai ser 3+3, seis; 4+4 é oito, e assim por diante.

G4A4: É verdade! Então, se continuar na $5^{a}$ posição vai ser dez, porque $5+5$ é dez.

Pesquisadora: Muito bem!

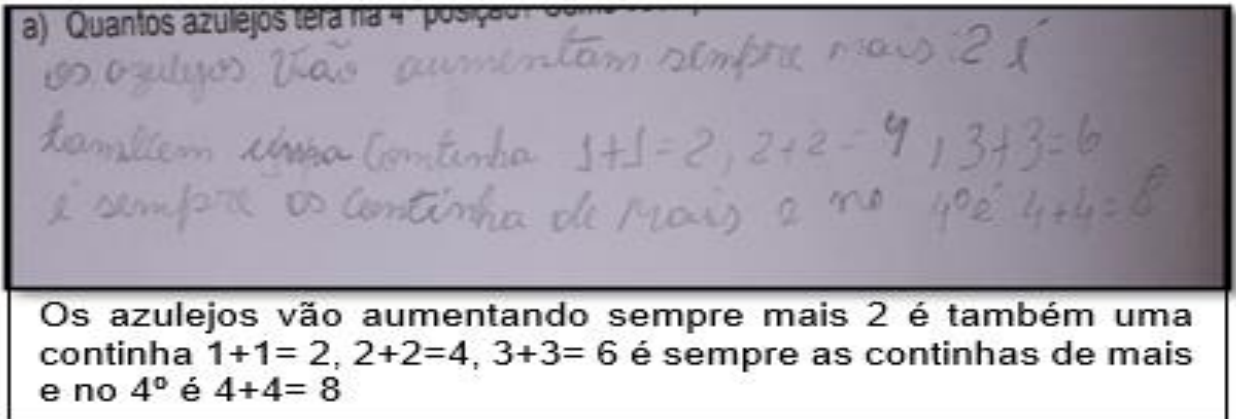

Figura 8: Justificativa do grupo G4 em relação à alternativa A da tarefa 2 (Acervo da Pesquisa)

O grupo G4 encontrou a quantidade correta de azulejos na $4^{\mathrm{a}}$ posição (oito azulejos), após perceber a regularidade presente em todos os termos da sequência: “em cada posição aumenta dois azulejos, na primeira é dois depois aumenta mais dois e fica quatro depois aumenta dois e fica seis e na quarta posição aumenta mais dois e fica oito" (G4A2). Além disso, o grupo generalizou explicitamente a relação entre a posição e a quantidade de azulejos: "Não, professora, acontece em todas as posições. Olha aqui, na posição 1 é só somar $1+1$ e vai ser dois azulejos, na posição 2 , soma $2+2$, vai ser quatro azulejos, na posição 3 vai ser 3+3, seis; 4+4 é oito, e assim por diante” (G4A4). A partir das justificativas apresentadas pelo grupo, foi definida uma regra geral para encontrar a quantidade de azulejos em qualquer posição da sequência. Para isso, bastou adicionar duas vezes o valor posicional. 


\section{Discussão de resultados}

Durante a condução da pesquisa, as tarefas foram o elemento principal da experiência de ensino, com o intuito de se pensar a relação ensino-aprendizagemavaliação. Vale ressaltar o entusiasmo e o estranhamento com que os estudantes as receberam, questionando a falta de "continhas" e da avaliação, o que, por meio de notas, mediria seu nível de acertos em cada tarefa. Na realidade, não reconheceram as tarefas como parte da disciplina de Matemática. Além disso, a ideia de justificar, por meio da escrita, como era pedido, parecia ser impossível, pois, segundo seus relatos, "na Matemática não se escreve, se resolve continhas". Por isso, foi um desafio desmistificar essas ideias e somente após a exploração das tarefas é que os grupos chegaram à conclusão de que Matemática não era somente números e operações, pois poderia estar relacionada, por exemplo, ao ato de pensar, refletir, explorar, levantar hipóteses, justificar e generalizar.

As tarefas do tipo exploratório-investigativa mostraram-se propícias para serem trabalhadas nos Anos Iniciais, principalmente por impulsionar o espírito investigativo dos estudantes, tão necessário para a aprendizagem da Matemática, desde sua origem até os dias atuais. Além disso, a inclusão desse tipo de atividade na turma apontou um caminho para a construção sólida do verdadeiro sentido da disciplina, ou seja, mostrou aos estudantes que a Matemática é uma construção humana, fruto de investigações, tentativas, erros e acertos. E, assim, contribuiu para que o sentido dessa ciência, em particular nos conteúdos algébricos, estivesse além dos números e operações. Além disso, o fato de as tarefas serem do tipo abertas, sem uma única resposta, também contribuiu para o desenvolvimento do pensamento algébrico dos estudantes, uma vez que estes se sentiram livres para explorar e justificar de acordo com seu entendimento, sem o receio de errar.

Todas as justificativas são ricas em informações e expressam o que o estudante sabe, bem como ajudam o professor a direcionar sua prática de ensino em prol da melhoria das aprendizagens. Em suma, as tarefas abertas do tipo exploratório-investigativas estimularam o interesse dos estudantes em desvendar o desconhecido e instigaram a curiosidade de encontrar soluções justificáveis, pois a fonte de interesse não era somente "dar uma resposta" e sim justificar, por meio de palavras escritas ou faladas, como eles pensaram e chegaram a uma determinada solução. 
$\mathrm{Na}$ fase de exploração das tarefas, os estudantes trabalharam em pequenos grupos, onde articularam estratégias, descobriram diferentes metodologias de resolução das tarefas, pois o caminho percorrido em busca de resposta foi fruto de debates, investigações e experimentações. Como resultado do trabalho coletivo, todos chegaram a respostas coerentes de acordo com o solicitado.

Neste contexto, é ainda de salientar que as tarefas de Álgebra, acima discutidas, criaram a oportunidade de os estudantes explorarem padrões e relações numéricas, generalizando-as, desenvolvendo o pensamento funcional e relacional. Além disso, eles ainda foram estimulados a explicitar e discutir as suas ideias, refletindo sobre elas. Nesta perspectiva, as tarefas mostraram-se pertinentes para verificar, na prática, a indissociabilidade entre ensino-aprendizagem-avaliação, pois foi possível experimentar esses três momentos de modo articulado em sala de aula. Na realidade, a avaliação aconteceu ao mesmo tempo do ensino, deixando de ser um momento isolado de classificação ou certificação para assumir um novo significado, que buscou refletir os saberes, dúvidas e dificuldades dos estudantes para direcionar os próximos passos. Vale ressaltar que, em nenhum momento, eles receberam feedback negativo, que desvalorizasse ou desqualificasse suas respostas e/ou ideias e, por essa razão, os grupos permaneceram motivados e seguros para expor suas percepções.

Este tipo de avaliação, também reconhecida como avaliação formativa, dedica-se a perceber o que os estudantes sabem, são capazes de fazer e o que precisam saber/fazer para melhorar as aprendizagens. Para isso, as interações entre professor e estudante são constantes, os feedbacks são contínuos e direcionados para ativar a capacidade cognitiva deles. Estes são assim motivados a refletir e a regular as suas aprendizagens, pois o verdadeiro sentido do feedback de qualidade é encorajá-los a melhorar a sua aprendizagem, melhorando para isso a sua motivação, autoestima e autonomia para os estudos. Dessa forma, é oportuno referir que o feedback deve ser organizado, diversificado e bem-distribuído entre os estudantes.

No entanto, durante a experiência para esta pesquisa, surgiram dificuldades na distribuição do feedback, decorrentes principalmente da grande quantidade de alunos na turma foco deste estudo. O número de estudantes em sala de aula provocou a formação de muitos grupos, dificultando o acompanhamento das equipes na mesma frequência, 
pois, enquanto a pesquisadora acompanhava determinado grupo, outros acabavam por se dispersar com facilidade. Consequentemente, os grupos que receberam menos feedback tiveram maiores dificuldades que os restantes no desenvolvimento do pensamento algébrico.

Pode-se assim afirmar que as quatro tarefas, do tipo exploratório-investigativas, que fizeram parte da investigação, foram potenciais para o desenvolvimento do pensamento algébrico dos estudantes, pois das 44 respostas apresentadas, em aproximadamente $80 \%$ houve a manifestação deste tipo de raciocínio.

Em suma, da análise de resultados, percebe-se que os estudantes aprenderam a definir uma regra geral; a identificar explicitamente relações entre as variáveis independente e dependente; a reconhecer e usar relações numéricas, propriedades das operações e o sinal de igualdade para além dos casos particulares, ou seja, desenvolveram o pensamento algébrico, por meio do pensamento funcional e relacional.

\section{Considerações finais}

Pode-se dizer que as tarefas representaram, para os estudantes, uma "novidade" e para uma das autoras desta pesquisa uma experiência nova, pois ainda não havia vivenciado, na prática, como tarefas poderiam articular ensino-aprendizagem-avaliação e, ao mesmo tempo, trabalhar a perspectiva do pensamento algébrico nos Anos Iniciais. Ainda assim, o presente estudo, de acordo com Barbosa (2019), mostrou que um ensino de caráter exploratório, centrado em tarefas, devidamente articulado com a aprendizagem e a avaliação, é o modelo que mais se adequa ao desenvolvimento do pensamento algébrico. $\mathrm{Na}$ verdade, o fato de as tarefas voltadas para o desenvolvimento do pensamento algébrico terem assumido um papel de destaque, sendo por meio delas que se ensinou, aprendeu e avaliou, bem como o de estas terem sido trabalhadas pelos estudantes em pequeno grupo, criaram um clima de cooperação entre eles, levando-os a uma maior participação em sala de aula, o que os ajudou a aprofundar os conteúdos algébricos trabalhados. Em suma, o trabalho com tarefas é promissor e pode estimular a construção sólida de conceitos relacionados com a Álgebra, minimizando dificuldades de aprendizagem futuras.

Neste ponto, ainda é importante salientar que a experiência de ensino possibilitou também conhecer o verdadeiro sentido da avaliação, ou seja, de que ela não deve ser um 
momento isolado do ensino-aprendizagem, uma vez que a sua função principal é a de regular e melhorar as aprendizagens dos estudantes, para tal, ofeedback fornecido a eles precisa ajudá-los a alcançar os objetivos implícitos nas tarefas.

Como possibilidade de pesquisa futura, considerando a importância do pensamento algébrico nos Anos Iniciais, é possível elaborar tarefas abertas que articulem o ensino-aprendizagem-avaliação de conceitos relacionados à noção intuitiva de função por meio de problemas, envolvendo a variação proporcional entre duas grandezas, mas sem a utilização de regra de três simples, pois, de acordo com os preceitos da BNCC, nos Anos Iniciais, não é recomendado o uso de letras para expressar generalizações.

Importa dizer também que, nesta pesquisa, as rubricas de avaliação eram potenciais. Porém, dado o limite para a conclusão do texto, as rubricas não foram exploradas, mas, podem ser um instrumento interessante para a investigação sobre ensino-aprendizagem-avaliação, considerando a avaliação criterial e contínua e não somente focada em resultados. As rubricas devem apresentar critérios de avaliação claros, construídos conjuntamente com os estudantes que, por sua vez, terão envolvimento prévio com o trabalho a ser avaliado, tornando-se também partícipes desse processo, além de proporcionar ao professor oportunidades de orientação para avaliar de modo transparente e objetivo. Essas são algumas possibilidades de investigações, a partir da experiência vivenciada nessa pesquisa, sobre os modos como tarefas exploratório-investigativas de ensino-aprendizagem-avaliação potencializam o desenvolvimento do pensamento algébrico de crianças nos Anos Iniciais.

\section{Referências}

BARBOSA, Elsa. A exploração de padrões num contexto de tarefas de investigação com alunos do $8^{\circ}$ ano de escolaridade. 2007. 119f. Dissertação (Mestrado em Educação) Escola de Ciências Sociais. Universidade de Évora. Évora.

BARBOSA, Elsa. Práticas de um professor, participação dos alunos e pensamento algébrico numa turma de $7^{\circ}$ ano de escolaridade. 2019. 312f. Tese (Doutorado em Ciências da Educação) - Instituto de Investigação e Formação Avançada. Universidade de Évora, Évora.

BECK, Vinicius Carvalho; SILVA, João Alberto. O estado da arte das pesquisas sobre o pensamento algébrico com crianças. Revemat, Florianópolis, v. 10, n. 2, p. 197-208, maio/ago. 2015. 
BLACK, Paul; WILIAM, Dylan. Assessment and classroom learning. Assessment in Education: principles, policy and practice, v. 5, n. 1, p. 7-74, jul. 1998.

BLACK, Paul; WILLIAM, Dylan. Developing the theory of formative assessment. Educational Assessment, Evaluation and Accountability, v. 21, n. 1, p. 5-31, jan. 2009.

BLANTON, Maria L. Algebra and the elementary classroom: transforming thinking, transforming practice. Portsmouth: Heinemann, 2008.

BLANTON, Maria L.; KAPUT, James J. Characterizing a classroom practice that promotes algebraic reasoning. Journal for Research in Mathematics Education, v. 36, n. 5, p. 412- 446, nov. 2005.

BORRALHO, António Manuel Águas; LUCENA, Isabel Cristina Rodrigues; BRITO, Maria Augusta Raposo de Barros Brito. Avaliar para melhorar as aprendizagens em Matemática. Belém: SBEM-PA, 2015.

BRASIL. Ministério da Educação. Secretaria de Educação Básica. Base Nacional Comum Curricular: Educação Infantil e Ensino Fundamental. Brasília: MEC/SEB, 2017.

CANAVARRO, Ana Paula. O pensamento algébrico na aprendizagem da Matemática nos primeiros anos. Quadrante, Lisboa, v. 16, n. 2, p. 81-118, jul./dez. 2007.

CANAVARRO, Ana Paula; OLIVEIRA, Hélia Margarida; MENEZES, Luís. Práticas de ensino exploratório da Matemática: o caso de Célia. In: ENCONTRO DE INVESTIGAÇÃO EM EDUCAÇÃO MATEMÁTICA, 2012, Castelo de Vide. Atas de EIEM: Práticas de ensino de Matemática. Lisboa: SPIEM, 2012, p. 255-265.

CARRAHER, David William; SCHLIEMANN, Analúcia Dias. Early algebra and algebraic reasoning. In: LESTER JR., Frank K. (Ed.). Second handbook of mathematics teaching and learning. Charlotte: Information Age Publishing, 2007, p. 669-705.

FERNANDES, Domingos. Articulação da aprendizagem, da avaliação e do ensino: questões teóricas, práticas e metodológicas. In: ALVES, Maria Palmira; DE KETELE, Jean-Marie. (Org.). Do currículo à avaliação, da avaliação ao currículo. Porto: Porto Editora, 2011a, p. 131-142.

FERNANDES, Domingos. Avaliação das aprendizagens: uma agenda, muitos desafios. Lisboa: Texto Editora, 2004.

FERNANDES, Domingos. Avaliar para melhorar as aprendizagens: análise e discussão de algumas questões essenciais. In: FIALHO, Isabel; SALGUEIRO, Hélio. (Org.). TurmaMais e sucesso escolar: contributos teóricos e práticos. Évora: CIEP-UEvora, 2011b. p. 81-107.

FIORENTINI, Dario; MIORIM, Maria Angela; MIGUEL, Antonio. Contribuição para um repensar a educação algébrica elementar. Pro-Posições, Campinas, v. 4, n. 1, p. 7890, mar. 1993.

FONSECA, Helena; BRUNHEIRA, Lina; PONTE, João Pedro. As actividades de 
investigação, o professor e a aula de Matemática. Lisboa: APM, 1999.

KIERAN, Carolyn. Overall commentary on early algebraization: perspectives for research and teaching. In: CAI, Jinfa; KNUTH, Eric. (Ed.). Early algebraization: a global dialogue from multiple perspectives. Heidelberg: Springer, 2011. p. 579-593.

LINS, Romulo Campos; GIMENEZ, Joaquim. Perspectivas em Aritmética e Álgebra para o século XXI. Campinas: Papirus, 1997.

MESCOUTO, Juliana Batista. Tarefas exploratório-investigativas para o desenvolvimento do pensamento algébrico nos anos iniciais: uma experiência para se pensar a relação ensino-aprendizagem-avaliação. 2019. 122f. Dissertação (Mestrado em Docência em Educação em Ciências e Matemáticas) — Instituto de Educação Matemática e Científica. Universidade Federal do Pará. Belém.

MESTRE, Célia Maria Martins Vitorino. $O$ desenvolvimento do pensamento algébrico de alunos do $4^{\circ}$ ano de escolaridade: uma experiência de ensino. 2014. 379f. Tese (Doutorado em Educação) - Instituto de Educação. Universidade de Lisboa. Lisboa.

OLIVEIRA, Vania Sara Doneda de; BASNIAK, Maria Ivete. O planejamento de aulas assentes no ensino exploratório de Matemática desenvolvidas no ensino remoto de emergência. Educação Matemática Debate, Montes Claros, v. 5, n. 11, p. 1-29, 2021.

PERRENOUD, Philippe. Avaliação: da excelência à regulação das aprendizagens-entre duas lógicas. Tradução de Patrícia Chittoni Ramos. Porto Alegre: Artmed, 1999.

PONTE, João Pedro, BRANCO, Neusa; MATOS, Ana. Álgebra no ensino básico. Lisboa: DGIDC, 2009.

PONTE, João Pedro. Explorar e investigar em Matemática: uma actividade fundamental no ensino e na aprendizagem. Revista Iberoamericana de Educación Matemática, v. 6, n. 21, p. 13-30, mar. 2010.

PONTE, João Pedro; NUNES, Cláudia Canha; QUARESMA, Marisa. Explorar, investigar, interagir na aula de Matemática: elementos fundamentais para a aprendizagem. In: SILVA, Adelmo Carvalho da; CARVALHO, Mercedes; RÊGO, Rogéria Gaudencio do. (Org.). Ensinar Matemática: formação, investigação e práticas docentes. Cuiabá: EdUFMT, 2012, p. 49-74.

RIBEIRO, Alessandro Jacques; CURY, Helena Noronha. Álgebra para a formação do professor: explorando os conceitos de equação e de função. Belo Horizonte: Autêntica, 2015.

VERSCHAFFEL, Lieven; GREER, Brian; DE CORTE, Erik. Whole number concepts and operations. In: LESTER, Frank K. (Ed.). Second handbook of mathematics teaching and learning. Charlotte: Information Age Publishing, 2007, p. 557-628.

VILLAS-BOAS, Benigna Maria de Freitas. Virando a escola do avesso por meio da avaliação. Campinas: Papirus, 2008. 